\title{
Metformin promotes isolated rat liver mitochondria impairment
}

\author{
Cristina Carvalho $\cdot$ Sónia Correia $\cdot$ Maria S. Santos $\cdot$ \\ Raquel Seiça $\cdot$ Catarina R. Oliveira $\cdot$ Paula I. Moreira
}

Received: 4 July 2007/ Accepted: 13 September 2007/Published online: 2 October 2007

(C) Springer Science+Business Media, LLC. 2007

\begin{abstract}
Metformin, a drug widely used in the treatment of type 2 diabetes, has recently received attention due to the new and contrasting findings regarding its effects on mitochondrial function. In the present study, we evaluated the effect of metformin in isolated rat liver mitochondria status. We observed that metformin concentrations $\geq 8 \mathrm{mM}$ induce an impairment of the respiratory chain characterized by a decrease in RCR and state 3 respiration. However, only metformin concentrations $\geq 10 \mathrm{mM}$ affect the oxidative phosphorylation system by decreasing the mitochondrial transmembrane potential and increasing the repolarization lag phase. Moreover, our results show that metformin does not prevent $\mathrm{H}_{2} \mathrm{O}_{2}$ production, neither protects against lipid peroxidation induced by the prooxidant pair $\mathrm{ADP} / \mathrm{Fe}^{2+}$. In addition, we observed that metformin exacerbates $\mathrm{Ca}^{2+}$-induced permeability transition pore opening by decreasing the capacity of mitochondria to accumulate $\mathrm{Ca}^{2+}$ and increasing the oxidation of thiol groups. Taken together, our results show
\end{abstract}

Cristina Carvalho and Sónia Correia contributed equally to this work.

C. Carvalho $\cdot$ S. Correia $\cdot$ M. S. Santos

Department of Zoology - Faculty of Sciences and Technology, University of Coimbra, Coimbra 3000-354, Portugal

M. S. Santos · R. Seiça · C. R. Oliveira · P. I. Moreira ( $ه)$

Center for Neuroscience and Cell Biology, University of

Coimbra, Coimbra 3004-517, Portugal

e-mail: venta@ci.uc.pt

R. Seiça · P. I. Moreira

Institute of Physiology - Faculty of Medicine, University of Coimbra, Coimbra 3000-354, Portugal

C. R. Oliveira

Institute of Biochemistry - Faculty of Medicine, University of Coimbra, Coimbra 3000-354, Portugal that metformin can promote liver mitochondria injury predisposing to cell death.

Keywords Liver - Metformin · Mitochondria ·

Oxidative phosphorylation system .

Permeability transition pore $\cdot$ Respiratory chain

\section{Introduction}

Metformin is an oral antihyperglycemic drug widely used in the treatment of type 2 diabetes [1]. The primary action of this biguanide derivative is the suppression of hepatic glucose production and the enhancement of peripheral glucose uptake. Therefore, metformin normalizes plasma glucose levels without any stimulation of insulin production and for this reason it is considered an insulin sensitizer. Despite the success of this antidiabetic agent in the treatment of type 2 diabetes, its mechanism(s) of action remain(s) unclear. Zhou et al. [2] reported that metformin activates AMP-activated protein kinase (AMPK), a major cellular regulator of lipid and glucose metabolism, in hepatocytes. Furthermore, it has been shown that metformin possesses a direct scavenging effect against oxygenated free radicals generated in vitro [3], and decreases intracellular production of reactive oxygen species (ROS) in aortic endothelial cells through the reduction of both $\mathrm{NAD}(\mathrm{P}) \mathrm{H}$ oxidase and/or the mitochondrial respiratory chain pathways [4]. Moreover, it has also been shown that metformin inhibits mitochondrial complex I activity leading to the impairment of mitochondrial function [5-7]. However, it has also been shown that metformin prevents the mitochondrial permeability transition pore (PTP) opening in both permeabilized and intact KB cells [8], and in permeabilized human microvascular endothelial 
cells (HMEC-1) [9]. In opposition, Isakovic et al. [10] reported that metformin acts as a PTP inducer in C6 rat glioma cell line.

Mitochondria are intracellular organelles mainly devoted to energy production but they also play a crucial role in the production of reactive species and the onset of cell death [11]. A common mechanism involved in mitochondrial dysfunction is the PTP which is modulated by several physiological factors $[12,13]$. Although $\mathrm{Ca}^{2+}$ is considered to be the most important inducer, matrix $\mathrm{pH}$, transmembrane electrical potential $\left(\Delta \Psi_{\mathrm{m}}\right), \mathrm{Mg}^{2+}, \mathrm{P}_{\mathrm{i}}$, cyclophilin D, oxidative stress and adenine nucleotides are also effective regulators, while the immunosuppressive agent cyclosporin A (CsA) is considered to be a specific inhibitor of PTP [13-15].

Due to the contradictory results concerning the action of metformin on mitochondrial status, in the present study, we aimed to evaluate the effect of metformin in isolated rat liver mitochondria. Our first task was the evaluation of the impact of increasing concentrations of metformin $(0.5,1,2$, 4,8 and $10 \mathrm{mM}$ ) in the mitochondrial respiratory chain and oxidative phosphorylation system. For that purpose, we analysed the respiratory indexes (RCR and ADP/O), $\Delta \Psi_{\mathrm{m}}$, repolarization level and repolarization lag phase. The second part of this study consisted of the evaluation of the effect of metformin in hydrogen peroxide $\left(\mathrm{H}_{2} \mathrm{O}_{2}\right)$ production, lipid peroxidation and $\mathrm{Ca}^{2+}$-induced PTP. The lipid peroxidation was evaluated by analysing TBARS formation and oxygen consumption, while the induction of PTP was characterized by analysing the $\Delta \Psi_{\mathrm{m}}, \mathrm{Ca}^{2+}$ fluxes and protein thiol groups' oxidation. The choice of rat liver mitochondria as experimental model was based on the fact that liver is the major site for the uptake and metabolism of drugs, liver mitochondria being primary targets for their hepatotoxicity [16].

\section{Materials and methods}

\section{Materials}

Metformin (1,1-dimethylbiguanide hydrochloride) was obtained from Sigma (Portugal). All the other chemicals were of the highest grade of purity commercially available. In the present study, we used metformin dissolved in distilled $\mathrm{H}_{2} \mathrm{O}$.

\section{Animals}

Male Wistar rats (10 weeks old) were housed in our animal colony (Laboratory Research Center, Faculty of Medicine, Coimbra, Portugal). They were maintained under controlled light (12 h day/night cycle) and humidity with free access (except in the fasting period) to water and powdered rodent chow (URF1; Charles River). Adhering to procedures approved by the Institutional Animal Care and Use Committee, the animals were killed by cervical displacement and decapitation.

\section{Isolation of liver mitochondria}

Mitochondria were isolated from liver by conventional methods [17] with slight modifications. Briefly, the liver mitochondria were isolated in a medium containing $250 \mathrm{mM}$ sucrose, $10 \mathrm{mM}$ Hepes, $0.5 \mathrm{mM}$ EGTA and $0.1 \%$ fat-free bovine serum albumin (BSA) (pH 7.4). EGTA and BSA were omitted from the final washing medium. The mitochondrial pellet was washed twice and suspended in the washing medium. Mitochondrial protein was determined by the biuret method [18] calibrated with BSA.

\section{Mitochondrial respiration measurements}

Oxygen consumption of isolated liver mitochondria was monitored polarographically with a Clark oxygen electrode (YSI Model 5331, Yellow Springs Inst) connected to a suitable recorder in a $1 \mathrm{ml}$ thermostated, water-jacketed closed chamber with magnetic stirring [19]. The reactions were carried out at $30^{\circ} \mathrm{C}$ in $1 \mathrm{ml}$ of the reaction medium (130 mM sucrose, $50 \mathrm{mM} \mathrm{KCl}, 2.5 \mathrm{mM} \mathrm{MgCl}_{2}, 2.5 \mathrm{mM}$ $\mathrm{KH}_{2} \mathrm{PO}_{4}, 100 \mu \mathrm{M}$ EGTA, $5 \mathrm{mM}$ Hepes and $\mathrm{pH}$ 7.4). Mitochondria $(1 \mathrm{mg} / \mathrm{ml})$ were incubated with metformin $1 \mathrm{~min}$ before the addition of $5 \mathrm{mM}$ glutamate $/ 2.5 \mathrm{mM}$ malate.

Membrane potential $\left(\Delta \Psi_{\mathrm{m}}\right)$ measurements

The mitochondrial transmembrane potential $\left(\Delta \Psi_{\mathrm{m}}\right)$ was monitored by evaluating transmembrane distribution of the lipophilic cation $\mathrm{TPP}^{+}$(tetraphenylphosphonium) with a $\mathrm{TPP}^{+}$-selective electrode prepared according to Kamo et al. [20] using an $\mathrm{Ag} / \mathrm{AgCl}$-saturated electrode (Tacussel, model MI 402) as reference. $\mathrm{TPP}^{+}$uptake has been measured from the decreased $\mathrm{TPP}^{+}$concentration in the medium sensed by the electrode. The potential difference between the selective electrode and the reference electrode was measured with an electrometer and recorded continuously in a Linear 1200 recorder. The voltage response of the $\mathrm{TPP}^{+}$electrode to $\log \left[\mathrm{TPP}^{+}\right]$was linear with a slope of $59 \pm 1$, in a good agreement with the Nernst equation. Reactions were carried out in a chamber with magnetic stirring in $1 \mathrm{ml}$ of the standard medium $(130 \mathrm{mM}$ sucrose, $50 \mathrm{mM} \mathrm{KCl}, 2.5 \mathrm{mM}$

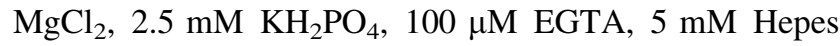


and $\mathrm{pH} 7.4$ supplemented with $2 \mu \mathrm{M}$ rotenone) containing $3 \mu \mathrm{M} \mathrm{TPP}^{+}$. This $\mathrm{TPP}^{+}$concentration was chosen in order to achieve high sensitivity in measurements and to avoid possible toxic effects on mitochondria [21]. The $\Delta \Psi_{\mathrm{m}}$ was estimated by the equation:

$$
\Delta \Psi \mathrm{m}(\mathrm{mV})=59 \log (\mathrm{v} / \mathrm{V})-59 \log \left(10^{\Delta \mathrm{E} / 59}-1\right)
$$

as indicated by Kamo et al. [20] and Muratsugu et al. [22]. $\mathrm{v}, \mathrm{V}$, and $\Delta \mathrm{E}$ stand for mitochondrial volume, volume of the incubation medium and deflection of the electrode potential from the baseline, respectively. This equation was derived assuming that $\mathrm{TPP}^{+}$distribution between the mitochondria and the medium follows the Nernst equation, and that the law of mass conservation is applicable. A matrix volume of $1.1 \mu \mathrm{l} / \mathrm{mg}$ protein was assumed. No correction was made for the "passive" binding contribution of $\mathrm{TPP}^{+}$to the mitochondrial membranes, because the purpose of the experiments was to show relative changes in potentials rather than absolute values. As a consequence, we can anticipate a slight overestimation on $\Delta \Psi_{\mathrm{m}}$ values. However, the overestimation is only significant at $\Delta \Psi_{\mathrm{m}}$ values below $90 \mathrm{mV}$, therefore, far from our measurements. Mitochondria $(1 \mathrm{mg} / \mathrm{ml})$ were incubated with metformin for $1 \mathrm{~min}$ before the addition of $5 \mathrm{mM}$ glutamate $/ 2.5 \mathrm{mM}$ malate. After a steady-state distribution of $\mathrm{TPP}^{+}$had been reached (ca. 1 min of recording), $\Delta \Psi_{\mathrm{m}}$ fluctuations recorded. In the PTP experiments, two or three pulses of $\mathrm{Ca}^{2+}$ (1st pulse: $50 \mathrm{nmol} \mathrm{Ca}^{2+} / \mathrm{mg}$ protein; 2nd and 3rd pulses: $40 \mathrm{nmol}$ $\mathrm{Ca}^{2+} / \mathrm{mg}$ protein) were added, and $\Delta \Psi_{\mathrm{m}}$ was recorded. CsA was added $2 \mathrm{~min}$ before $\mathrm{Ca}^{2+}$ addition.

Measurement of hydrogen peroxide $\left(\mathrm{H}_{2} \mathrm{O}_{2}\right)$ levels

The $\mathrm{H}_{2} \mathrm{O}_{2}$ levels were measured fluorimetrically using a modification of the method described by Barja [23]. Briefly, liver mitochondria $(0.375 \mathrm{mg})$ were incubated at $30^{\circ} \mathrm{C}$ with $5 \mathrm{mM}$ glutamate $/ 2.5 \mathrm{mM}$ malate in $1.5 \mathrm{ml}$ of phosphate buffer, $\mathrm{pH} 7.4$, containing $0.1 \mathrm{mM}$ EGTA,

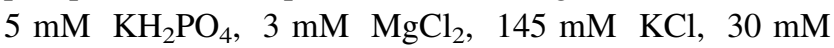
Hepes, $0.1 \mathrm{mM}$ homovalinic acid and $6 \mathrm{U} / \mathrm{ml}$ horseradish peroxidase in the absence or presence of metformin. After $15 \mathrm{~min}$, the reaction was stopped with $0.5 \mathrm{ml}$ cold stop solution (0.1 M glycine, $25 \mathrm{mM}$ EDTA-NaOH, $\mathrm{pH} 12$ ). Fluorescence of supernatants was determined at $312 \mathrm{~nm}$ excitation and $420 \mathrm{~nm}$ emission wavelengths. The $\mathrm{H}_{2} \mathrm{O}_{2}$ levels were calculated using a standard curve of $\mathrm{H}_{2} \mathrm{O}_{2}$.

Measurement of lipid peroxidation

The extent of lipid peroxidation was evaluated by oxygen consumption monitored polarographically at $30^{\circ} \mathrm{C}$ using a
Clark-type oxygen electrode (YSI Model 5331, Yellow Springs Inst) placed in a glass chamber equipped with magnetic stirring [24]. Reactions were carried out in $1 \mathrm{ml}$ of reaction medium containing $175 \mathrm{mM} \mathrm{KCl}, 10 \mathrm{mM}$ Tris- $\mathrm{HCl}$, $\mathrm{pH} 7.4$ and $1 \mathrm{mg}$ of protein. Reactions were started by the addition of $1 \mathrm{mM}$ ADP/ $0.1 \mathrm{mM} \mathrm{Fe}{ }^{2+}$, and the changes in oxygen tension were calculated assuming a concentration of $240 \mathrm{nmol} \mathrm{O} / \mathrm{ml}$. Mitochondria were incubated with metformin 1 min before the addition of ADP/ $/ \mathrm{Fe}^{2+}$. The extent of lipid peroxidation was also determined by measuring thiobarbituric acid reactive substances (TBARS), using the thiobarbituric acid assay, according to a modified procedure as described elsewhere [24]. The amount of TBARS formed was calculated using a molar extinction coefficient of $1.56 \times 10^{5} \mathrm{M}^{-1} \mathrm{~cm}^{-1}$ and expressed as nmol TBARS/mg protein.

\section{Measurements of $\mathrm{Ca}^{2+}$ fluxes}

Mitochondrial $\mathrm{Ca}^{2+}$ fluxes were measured by monitoring the changes in $\mathrm{Ca}^{2+}$ concentration in the reaction medium using a $\mathrm{Ca}^{2+}$-selective electrode [25]. The reactions were conducted in an open vessel with magnetic stirring in $1 \mathrm{ml}$ of the standard reaction medium supplemented with $5 \mathrm{mM}$ glutamate $/ 2.5 \mathrm{mM}$ malate and $90 \mathrm{nmol} / \mathrm{mg}$ protein of $\mathrm{CaCl}_{2}$. The reaction started with the addiction of mitochondria. Metformin was added 1 min after mitochondria addition. $\mathrm{CsA}$ was added $2 \mathrm{~min}$ before $\mathrm{Ca}^{2+}$ addition.

\section{Mitochondrial thiol oxidation}

A variation of Ellman's method was used to determine the mitochondrial content in protein thiol groups [26]. At the end of the $\Delta \Psi_{\mathrm{m}}$ experiments, $750 \mu$ of each mitochondrial suspension were frozen and thawed three times. Then, $750 \mu \mathrm{l}$ of sulphosalicilic acid $4 \%$ were added. The samples were submitted to centrifugation at 10,000 rpm for $15 \mathrm{~min}$. The supernatant was removed and the pellet was suspended in $1 \mathrm{ml}$ of phosphate buffer $100 \mathrm{mM}, \mathrm{pH}$. The suspension was sonicated and diluted to $2.6 \mathrm{ml}$ in phosphate buffer medium containing $385 \mathrm{mM}$ DTNB [5,5'-dithiobis (2-nitrobenzoic) acid]. After $15 \mathrm{~min}$ of reaction, the absorption was measured at $412 \mathrm{~nm}$, and the results were expressed as percentage of control.

\section{Statistical analysis}

Results are presented as mean \pm SEM of the indicated number of experiments. Statistical significance was determined using the student $t$-test and one-way ANOVA test for multiple comparisons, followed by the posthoc TukeyKramer test. 


\section{Results}

High concentrations of metformin impair mitochondrial respiration

We observed that mitochondria energized with $5 \mathrm{mM}$ glutamate $/ 2.5 \mathrm{mM}$ malate, a substrate for complex I, and pre-incubated with concentrations of metformin $\geq 8 \mathrm{mM}$ presented a significant reduction on state 3 respiration (ADP-stimulated respiration), while state 4 (substrate alone) was only slightly reduced in the presence of the same concentrations of metformin when compared with the control condition (Fig. 1a and b). Accordingly, RCR was significantly reduced in the presence of metformin concentrations $\geq 8 \mathrm{mM}$ when compared with control condition (Fig. 1c). However, ADP/O ratio remained statistically unchanged (Fig. 1d).

High concentrations of metformin impair the oxidative phosphorylation system

$\Delta \Psi_{\mathrm{m}}$ is at the centre of the cell's interactions, controlling, among other processes, ATP synthesis, mitochondrial $\mathrm{Ca}^{2+}$ accumulation and superoxide $\left(\mathrm{O}_{2}^{\bullet-}\right)$ generation. In the control conditions, the $\Delta \Psi_{\mathrm{m}}$ developed by liver mitochondria after energization with $5 \mathrm{mM}$ glutamate/2.5 mM malate was $-216.3 \pm 3.4 \mathrm{mV}$. As shown in Table 1 , only the highest concentration of metformin tested, $(10 \mathrm{mM})$ induced a significant decrease in the $\Delta \Psi_{\mathrm{m}}$ and a significant increase in the repolarization lag phase (time necessary for ADP phosphorylation), when compared with control condition. However, the repolarization level (capacity of mitochondria to re-establish the $\Delta \Psi_{\mathrm{m}}$ after the ADP phosphorylation) remained statistically unchanged (Table 1).

Metformin does not protect against oxidative stress

The production of $\mathrm{H}_{2} \mathrm{O}_{2}$ by mitochondria gives an indication about the propensity of mitochondria to originate and/ or exacerbate oxidative stress. At control conditions, energized mitochondria produced $1964 \pm 406.3 \mathrm{pmol}$ $\mathrm{H}_{2} \mathrm{O}_{2} / \mathrm{mg}$ protein/15 min. We observed that metformin induced a slight, although not significant, increase in $\mathrm{H}_{2} \mathrm{O}_{2}$ production (Fig. 2). The $\mathrm{H}_{2} \mathrm{O}_{2}$-scavanging enzyme catalase was used as positive control. As expected, catalase significantly decreased the production of $\mathrm{H}_{2} \mathrm{O}_{2}$ when compared with the other conditions tested (Fig. 2).

Oxygen consumption and TBARS levels were evaluated to determine the extent of lipid peroxidation induced by $\mathrm{ADP} / \mathrm{Fe}^{2+}$. We observed that metformin (independently of the concentrations tested) did not protect against lipid
Fig. 1 Effect of metformin on states 3 (a) and 4 (b) of respiration, $\mathrm{RCR}(\mathbf{c})$ and $\mathrm{ADP} / \mathrm{O}$ ratio (d) of freshly isolated liver mitochondria. Mitochondria $(1 \mathrm{mg})$ in $1 \mathrm{ml}$ of the reaction medium were energized with $5 \mathrm{mM}$ glutamate $/ 2.5 \mathrm{mM}$ malate. Mitochondria were incubated with metformin for $1 \mathrm{~min}$, at $30^{\circ} \mathrm{C}$, before mitochondria energization. Data are the mean \pm SEM of six independent experiments. Statistical significance: $* * * P<0.001 ; * P<0.05$, when compared with control condition (mitochondria without metformin). \#\#P<0.01; $\# P<0.05$, when compared with mitochondria incubated with $0.5 \mathrm{mM}$ metformin. $\$ \$ P<0.01$, when compared with mitochondria incubated with $1 \mathrm{mM}$ metformin
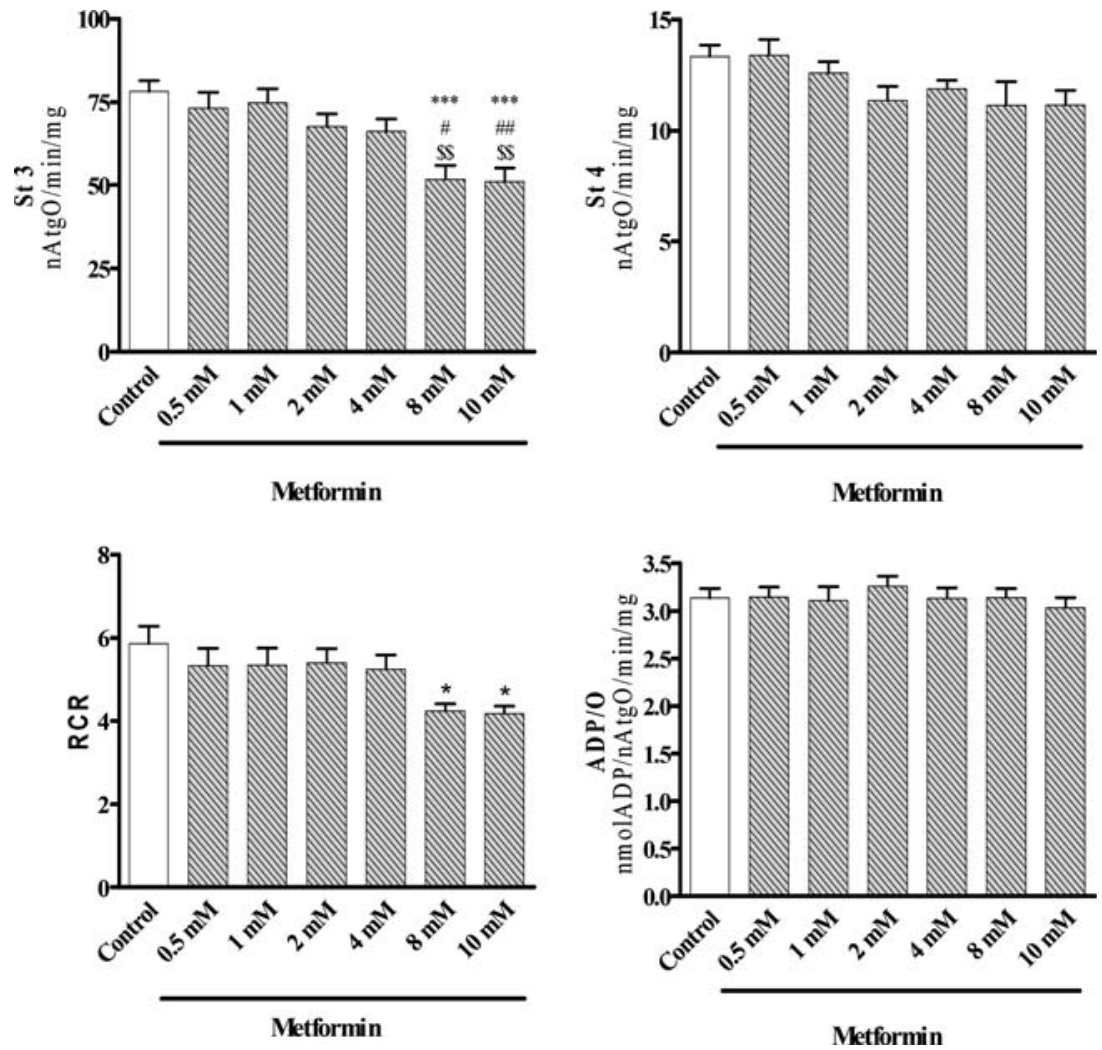
Table 1 Effect of metformin in the mitochondrial oxidative phosphorylation system $\left(\Delta \Psi_{\mathrm{m}}\right.$, repolarization level and repolarization lag phase)

\begin{tabular}{lrrrrrrr}
\hline & \multicolumn{1}{c}{ Metformin } & & & & \\
\cline { 2 - 7 } & \multicolumn{1}{c}{ Control } & \multicolumn{1}{c}{$0.5 \mathrm{mM}$} & \multicolumn{1}{c}{$1 \mathrm{mM}$} & $2 \mathrm{mM}$ & $4 \mathrm{mM}$ & $8 \mathrm{mM}$ & $10 \mathrm{mM}$ \\
\hline$\Delta \Psi_{\mathrm{m}}(-\mathrm{mV})$ & $216.3 \pm 3.40$ & $211.3 \pm 7.49$ & $213.6 \pm 4.85$ & $211.2 \pm 5.73$ & $214.3 \pm 3.28$ & $211.7 \pm 2.32$ & $208.6 \pm 3.43^{* *}$ \\
Repolarization level $(-\mathrm{mV})$ & $175.2 \pm 3.36$ & $172.8 \pm 3.18$ & $174.0 \pm 3.76$ & $174.6 \pm 3.45$ & $173.5 \pm 2.50$ & $175.7 \pm 2.58$ & $174.1 \pm 4.02$ \\
Repolarization lag phase (min) & $0.86 \pm 0.19$ & $0.96 \pm 0.25$ & $0.98 \pm 0.23$ & $1.11 \pm 0.12$ & $1.10 \pm 0.14$ & $1.14 \pm 0.18$ & $1.19 \pm 0.15^{* *}$ \\
\hline
\end{tabular}

The oxidative phosphorylation parameters were evaluated using freshly isolated liver mitochondria (1 $\mathrm{mg})$ in $1 \mathrm{ml}$ of the reaction medium supplemented with $3 \mu \mathrm{M} \mathrm{TPP}{ }^{+}$and energized with $5 \mathrm{mM}$ glutamate $/ 2.5 \mathrm{mM}$ malate. Mitochondria were incubated with metformin for $1 \mathrm{~min}$, at $30^{\circ} \mathrm{C}$, before mitochondria energization. Data are the mean \pm SEM of six independent experiments. Statistical significance: $* * P<0.01$ when compared to control condition (mitochondria without metformin)

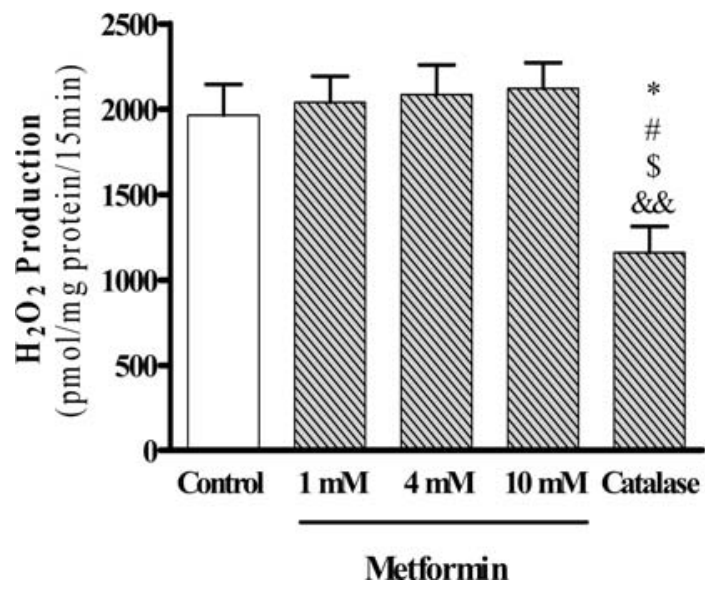

Fig. 2 Effect of metformin on hydrogen peroxide production. Liver mitochondria were incubated under conditions as described in Material and methods section. Data are the mean \pm SEM of four independent experiments. $* P<0.05$, when compared with control condition; $\$ P<0.05$, when compared with mitochondria incubated with $1 \mathrm{mM}$ metformin; $\# P<0.05$, when compared with mitochondria incubated with $4 \mathrm{mM}$ metformin; $\& \& P<0.01$, when compared with mitochondria incubated with $10 \mathrm{mM}$ metformin

peroxidation induced by the pro-oxidant pair $\mathrm{ADP} / \mathrm{Fe}^{2+}$ (Fig. 3a and b).

\section{Metformin exacerbates PTP induction}

The $\Delta \Psi_{\mathrm{m}}$ drop is a typical phenomenon that follows the induction of the PTP. In control conditions (Fig. 4a), we observed that the addition of mitochondrial substrate induced a $\Delta \Psi_{\mathrm{m}}$ of $\approx-215 \mathrm{mV}$. The first pulse of $\mathrm{Ca}^{2+}$ $(50 \mathrm{nmol} / \mathrm{mg}$ protein) leads to a rapid depolarization (decrease of $\Delta \Psi_{\mathrm{m}}$ ) followed by a smaller repolarization (recover of $\Delta \Psi_{\mathrm{m}}$ ). The depolarization was due to the entry of $\mathrm{Ca}^{2+}$ into the electronegative mitochondrial matrix, followed by the efflux of $\mathrm{H}^{+}$in an attempt to restore the $\Delta \Psi_{\mathrm{m}}$. Then, a second pulse of $40 \mathrm{nmol} \mathrm{Ca}{ }^{2+} / \mathrm{mg}$ protein leads to a rapid depolarization followed by a partial repolarization, and since mitochondria were incapable to sustain the accumulated $\mathrm{Ca}^{2+}$, they depolarized completely, which is an indication of the PTP induction (Fig. 4a). Mitochondria can tolerate a certain amount of $\mathrm{Ca}^{2+}$, but ultimately their capacity to adapt to $\mathrm{Ca}^{2+}$ loads is overwhelmed, and mitochondria depolarize completely due to a profound change in the inner membrane permeability. As observed in Fig. 4, metformin exacerbated the opening of PTP in a concentration-dependent manner by decreasing the repolarization capacity of mitochondria after the second addition of $\mathrm{Ca}^{2+}$, i.e., metformin decreased the time needed for pore induction. Since the mitochondrial collapse of the $\Delta \Psi_{\mathrm{m}}$, associated to $\mathrm{Ca}^{2+}$ overload, is related to the PTP opening, experiments were performed to further confirm the induction of the PTP opening by studying the $\mathrm{Ca}^{2+}$ retention by energized mitochondria. Figure $4 \mathrm{~b}$ shows that mitochondria incubated with $90 \mathrm{nmol} \mathrm{Ca}^{2+} / \mathrm{mg}$ protein and energized with $5 \mathrm{mM}$ glutamate $/ 2.5 \mathrm{mM}$ malate, rapidly accumulated the $\mathrm{Ca}^{2+}$ added to the reaction medium, but became unable to retain the accumulated $\mathrm{Ca}^{2+}$ due to the opening of PTP (Fig. 4b). Interestingly, we observed that metformin exacerbated $\mathrm{Ca}^{2+}$-induced PTP opening in a concentrationdependent manner (Fig. 4b). The presence of $0.85 \mu \mathrm{M} \mathrm{CsA}$, the specific inhibitor of PTP, added 2 min prior to $\mathrm{Ca}^{2+}$, afforded a clear protection of mitochondria (Fig. 4a and b), since mitochondria was able to accumulate and retain the $\mathrm{Ca}^{2+}$ present in the medium. Opening of PTP is also stimulated by the alteration of protein thiol redox status (-SH/SS-). Figure 5 shows that $50 \mathrm{nmol}$ of $\mathrm{Ca}^{2+}$ induced only a slight decrease in the amount of thiol groups. However, $90 \mathrm{nmol}$ of $\mathrm{Ca}^{2+} / \mathrm{mg}$ protein induced a significant decrease in thiol groups when compared with control condition. Similarly, we observed that mitochondria incubated with metformin and $50 \mathrm{nmol} \mathrm{Ca}{ }^{2+} / \mathrm{mg}$ protein presented a significant decrease of thiol groups when compared with control condition (Fig. 5). However, metformin per se did not affect thiol groups (data not shown).

\section{Discussion}

This study shows that only high concentrations of metformin impair liver mitochondrial respiratory chain and 

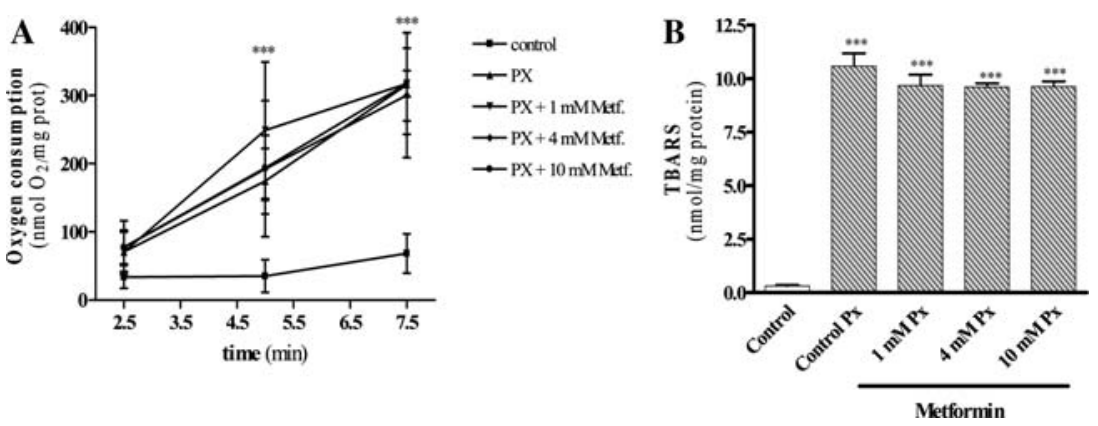

Fig. 3 Effect of metformin on lipid peroxidation (Px): Oxygen consumption (a) and TBARS levels (b). Mitochondria were incubated at $1 \mathrm{mg} / \mathrm{ml}$ under standard conditions as described in the Material and methods section. Mitochondria were incubated with metformin for
$1 \mathrm{~min}$, at $30^{\circ} \mathrm{C}$, before the addition of $\mathrm{ADP} / \mathrm{Fe}^{2+}$. Data shown represent mean \pm SEM from six animals for each condition studied. Statistical significance: $* * * P<0.001$, when compared with control condition
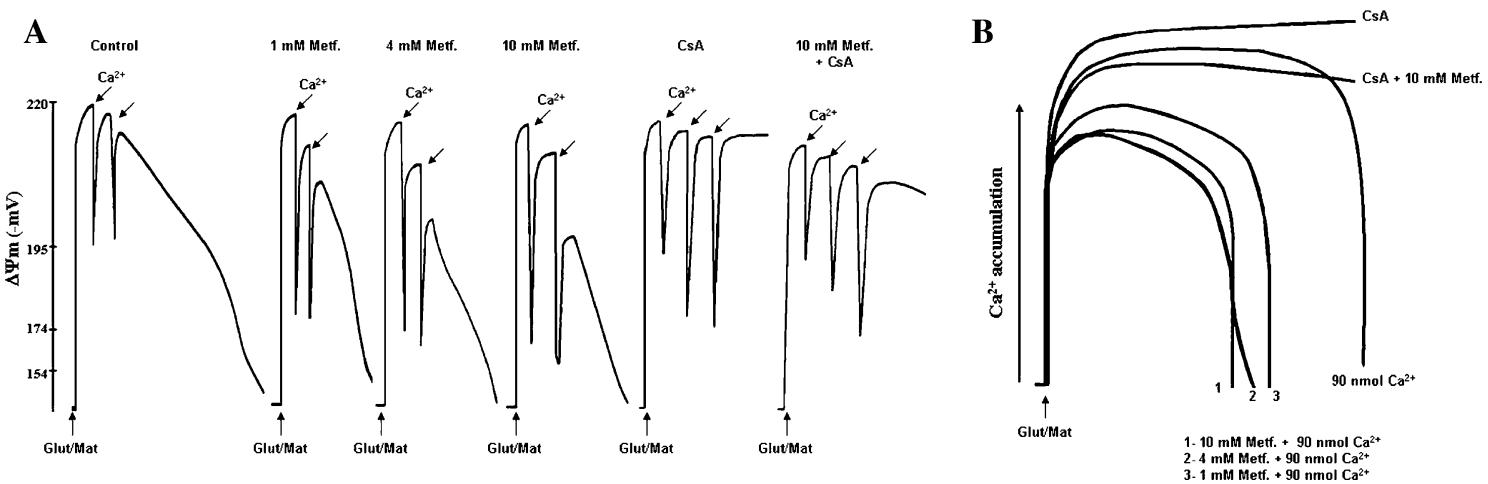

Fig. 4 Effect of metformin on mitochondrial permeability transition pore induction: susceptibility to $\mathrm{Ca}^{2+}$ addition $\left[\Delta \Psi_{\mathrm{m}}(\mathbf{a})\right.$ and calcium fluxes (b)]. Freshly isolated liver mitochondria $(1 \mathrm{mg})$ in $1 \mathrm{ml}$ of the reaction medium supplemented with $3 \mu \mathrm{M} \mathrm{TPP}{ }^{+}$were energized with $5 \mathrm{mM}$ glutamate $2.5 \mathrm{mM}$ malate. $\mathrm{Ca}^{2+}$ (1st pulse: $50 \mathrm{nmol} \mathrm{Ca}{ }^{2+} / \mathrm{mg}$

oxidative phosphorylation system. However, we observed that metformin exacerbates the PTP opening in a concentration-dependent manner. Furthermore, metformin is unable to protect against oxidative stress-related events.

Despite the progress made in recent studies [2, 5, 8, 27], the cellular action of metformin is still not fully understood. Previous data from the literature indicates that metformin inhibits the enzymatic activity of complex I, and impairs cell respiration [5-7]. Owen et al. [6] suggested that the inhibition of mitochondrial complex I contributes to metformin's antidiabetic action by restraining hepatic gluconeogenesis while increasing glucose utilization in peripheral tissues. El-Mir et al. [5] reported that metformin (1-10 $\mathrm{mM})$ mildly inhibits the respiratory chain, but only in intact cells and not in isolated mitochondria or permeabilized cells. However, the lack of effect of metformin on isolated mitochondria has been challenged by results showing that metformin can directly inhibit mitochondrial complex I $[6,28]$. Similarly, we observed that metformin affects directly isolated liver mitochondria by decreasing state 3 of respiration (Fig. 1a) and RCR (Fig. 1b). In protein; 2nd and 3rd pulses: $40 \mathrm{nmol} \mathrm{Ca}{ }^{2+} / \mathrm{mg}$ protein) was added $1.5 \mathrm{~min}$ after mitochondria energization. $0.85 \mu \mathrm{M}$ CsA was added $2 \mathrm{~min}$ before $\mathrm{Ca}^{2+}$ addition. The traces are typical of six independent experiments

contrast to Owen et al. [6], who reported that the addition of metformin to rat liver mitochondria oxidizing $5 \mathrm{mM}$ glutamate $/ 1 \mathrm{mM}$ malate gives no inhibition over a period of $5 \mathrm{~min}$ at $30^{\circ} \mathrm{C}$, even at concentrations as high as $10 \mathrm{mM}$, we observed an immediate effect of metformin. Furthermore, we observed that the impairment of the respiratory chain occur from concentrations of metformin above $4 \mathrm{mM}$. In opposition, Brunmair et al. [28] reported that metformin in the range of 3-30 $\mu \mathrm{M}$ already inhibits isolated liver mitochondria. The discrepancies between studies could be due to differences in the methodology used, such as mitochondria isolation procedures and differences in the temperature used in the assays. It has been previously demonstrated that the action of metformin is temperature-dependent [5]. We also observed that high concentrations of metformin impair the oxidative phosphorylation system (Table 1), that is in accordance with a previous study demonstrating that metformin causes mitochondrial depolarization [10].

The plasma concentrations of metformin found in patients are about 10-20 $\mu \mathrm{M}[1,29,30]$. However, the 


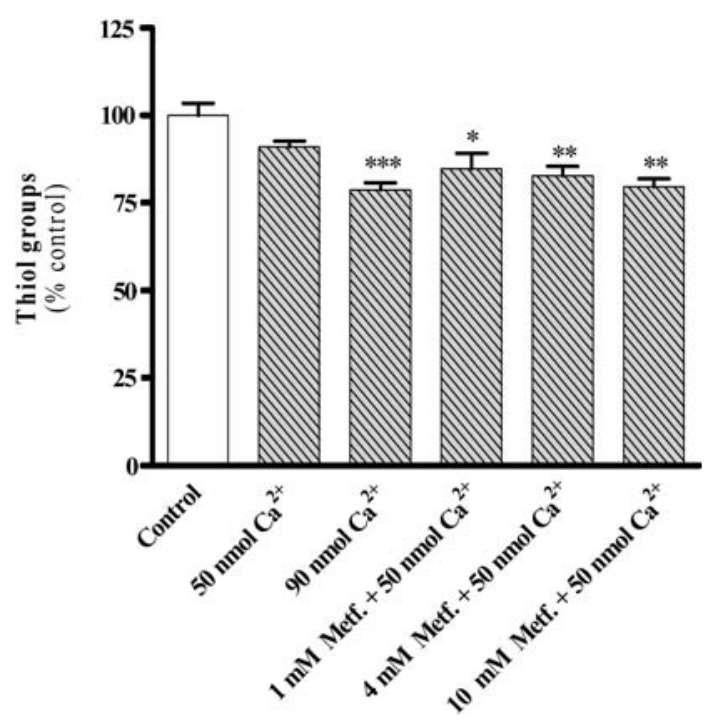

Fig. 5 Effect of metformin on mitochondrial protein thiol groups. Freshly isolated mitochondria $(1 \mathrm{mg})$ in $1 \mathrm{ml}$ of the reaction medium were energized with $5 \mathrm{mM}$ glutamate $/ 2.5 \mathrm{mM}$ malate. Mitochondria were incubated with metformin for $1 \mathrm{~min}$, at $30^{\circ} \mathrm{C}$, before mitochondria energization. $90 \mathrm{nmol} \mathrm{Ca}^{2+} / \mathrm{mg}$ protein was added after mitochondria energization. Data are the means \pm SEM of four independent experiments. $* * * P<0.001 ; * * P<0.01 ; * P<0.05$, when compared with control condition

liver receives the majority of the blood via the portal vein, which may contain concentrations of metformin substantially higher than those present in the general circulation [31]. Thus, a significant impact of metformin in liver mitochondria of patients treated with this drug would be predicted. Additionally, the positive charge on metformin could account for its accumulation within the matrix of energized mitochondria driven by the $\Delta \Psi_{\mathrm{m}}$, and such energy-dependent accumulation of metformin within the matrix has been shown to occur experimentally [32]. Indeed, it has been estimated that metformin accumulate 1,000-fold within the mitochondrial matrix [6]. In this line, the range of metformin concentrations used in this study embraces concentrations that approach the therapeutic ones. The highest concentrations of metformin (above the therapeutic range) were used to evaluate the potential concentration-dependent effects of this drug.

Lipid peroxidation is a process whereby free radicals "steal" electrons from the lipids, resulting in cell damage and increased production of free radicals [33]. Recently, Majithiya and Balaraman [34] reported that metformin protects liver, kidney and aorta tissues against lipid peroxidation promoted by streptozotocin-induced diabetes. It has also been shown that metformin decreases the level of lipid peroxidation markers in low-density and high-density lipoprotein particles obtained from adult type 2 diabetic patients [35]. However, our in vitro study shows that metformin does not protect against mitochondrial lipid peroxidation induced by the pro-oxidant pair ADP/Fe ${ }^{2+}$ (Fig. 3a and b), suggesting that the decrease in lipid peroxidation observed in the previous studies are not the result of a direct action of metformin but, probably, the result of its antihyperglycemic effects or the activation of AMPK [36]. Previously, Bonnefont-Rousselot et al. [3] reported that metformin in vitro is able to scavenge hydroxyl $\left(\mathrm{HO}^{\circ}\right)$ but not $\mathrm{O}_{2}^{-}$, and that $\mathrm{H}_{2} \mathrm{O}_{2}$ did not react with metformin. Our results show that metformin does not prevent $\mathrm{H}_{2} \mathrm{O}_{2}$ production (Fig. 2) and, instead, it elicits a slight increase in the levels of this reactive specie, probably resulting from the inhibition of mitochondrial complex I (Fig. 1a and b). A recent study showed that metformin in confluent $\mathrm{C} 6$ cultures causes massive induction of caspase-dependent apoptosis, associated with c-Jun $\mathrm{N}$-terminal kinase (JNK) activation, mitochondrial depolarization and oxidative stress [10]. Previously, Kowaltowski et al. [37] suggested that the rise in the production of endogenous mitochondrial ROS, including $\mathrm{H}_{2} \mathrm{O}_{2}$, facilitates the process of PTP opening. Indeed, we observed that metformin exacerbates $\mathrm{Ca}^{2+}$-induced PTP opening (Figs. 4 and 5) probably due to the slight increase in $\mathrm{H}_{2} \mathrm{O}_{2}$ production (Fig. 2), mitochondrial depolarization (Table 1) and inhibition of the respiratory chain (Fig. 1a and c). It is well known that the collapse of $\Delta \Psi_{\mathrm{m}}$ and the uncoupling of the electron transport chain promotes the PTP $[11,38]$. The PTP causes a non-selective permeabilization of the inner mitochondrial membrane typically promoted by the accumulation of excessive quantities of $\mathrm{Ca}^{2+}$ ions and stimulated by a variety of compounds or conditions [39]. In this study, the classic inductor $\mathrm{Ca}^{2+}$ was used to induce the PTP opening (Figs. 4 and 5). $\mathrm{Ca}^{2+}$ uptake is concentrationdependent, with the higher concentrations of metformin leading to a lower amount of $\mathrm{Ca}^{2+}$ being accumulated by mitochondria, which indicates a continuous cycling of $\mathrm{Ca}^{2+}$ due to the PTP induction. These results are in accordance with recent data demonstrating that metformin-triggered apoptosis is completely prevented by the specific inhibitor of the PTP, CsA [10]. We also observed that the effect of metformin in $\mathrm{Ca}^{2+}$-induced PTP opening is prevented by CsA (Figs. 4 and 5). The PTP opening allows the equilibration of ions and respiratory substrate between cytosol and mitochondrial matrix leading to the reduction of $\Delta \Psi_{\mathrm{m}}$ [40] that is linked to depletion of GSH [41]. Indeed, the mitochondrial pore induction is intimately associated with GSH and protein thiol redox state [42]. When protein thiol groups from the inner mitochondrial membrane are oxidized, the pore complex suffers conformational changes resulting in a large nonselective permeabilization of the mitochondrial membrane [43]. Accordingly, we observed that metformin potentiates the effect of $\mathrm{Ca}^{2+}$ on thiol groups' oxidation (Fig. 5).

Altogether, our results show that metformin can promote liver mitochondria injury and predispose to cell death, 
which is in accordance with previous case reports [44, 45] describing the existence of metformin-induced hepatotoxicity. Since liver mitochondria of diabetic patients under metformin treatment are potentially exposed to high levels of this antidiabetic agent, the potential side effects of metformin should be carefully considered.

\section{References}

1. Bailey CJ, Turner RC (1996) Metformin. New Engl J Med 334:574-579

2. Zhou G, Myers R, Li Y et al (2001) Role of AMP-activated protein kinase in mechanism of metformin action. J Clin Invest 108:1167-1174

3. Bonnefont-Rousselot D, Raji B, Walrand S et al (2003) An intracellular modulation of free radical production could contribute to the beneficial effects of metformin towards oxidative stress. Metabolism 52:586-589

4. Ouslimani N, Peynet J, Bonnefont-Rousselot D et al (2005) Metformin decreases intracellular production of reactive oxygen species in aortic endothelial cells. Metabolism 54:829-834

5. El-Mir MY, Nogueira V, Fontaine E et al (2000) Dimethylbiguanide inhibits cell respiration via an indirect effect targeted on the respiratory chain complex I. J Biol Chem 275:223-228

6. Owen MR, Doran E, Halestrap AP (2000) Evidence that metformin exerts its anti-diabetic effects through inhibition of complex 1 of the mitochondrial respiratory chain. Biochem J 348:607-614

7. Detaille D, Guigas B, Leverve X et al (2002) Obligatory role of membrane events in the regulatory effect of metformin on the respiratory chain function. Biochem Pharmacol 63:1259-1272

8. Guigas B, Detaille D, Chauvin C et al (2004) Metformin inhibits mitochondrial permeability transition and cell death: a pharmacological in vitro study. Biochem J 382:877-884

9. Detaille D, Guigas B, Chauvin C et al (2005) Metformin prevents high-glucose-induced endothelial cell death trough a mitochondrial permeability transition dependent process. Diabetes 54:2179-2187

10. Isakovic A, Harhaji L, Stevanovic D et al (2007) Dual antiglioma action of metformin: cell cycle arrest and mitochondria-dependent apoptosis. Cell Mol Life Sci 64:1290-1302

11. Kroemer G, Petit P, Zamzami N et al (1995) The biochemistry of programmed cell death. FASEB J 9:1277-1287

12. Rosser BG, Gores GJ (1995) Liver cell necrosis: cellular mechanisms and clinical implications. Gastroenterology 108:252-275

13. Bernardi P, Scorrano L, Colonna R et al (1999) Mitochondria and cell death. Mechanistic aspects and methodological issues. Eur J Biochem 264:687-701

14. Fontaine E, Eriksson O, Ichas F et al (1998) Regulation of the permeability transition pore in skeletal muscle mitochondria. Modulation by electron flow through the respiratory chain complex I. J Biol Chem 273:12662-12668

15. Scorrano L, Korsmeyer SJ (2003) Mechanisms of cytochrome c release by proapoptotic BCL-2 family members. Biochem Biophys Res Commun 304:437-444

16. Jaeschke H, Gores GJ, Cederbaum AI et al (2002) Mechanisms of hepatotoxicity. Toxicol Sci 65:166-176

17. Gazotti P, Malmstron K, Crompton M (1979) A laboratory manual on transport and bioenergetics. In: Carafoli E, Semenza G (eds) Membrane biochemistry. Springer-Verlag New York Inc., New York, pp 62-69

18. Gornall AG, Bardawill CJ, David MM (1949) Determination of serum proteins by means of the biuret reaction. J Biol Chem 177:751-766
19. Estabrook RE (1967) Mitochondrial respiratory control and the polarographic measurement of ADP/O ratios. Meth Enzymol $10: 41-47$

20. Kamo N, Muratsugu M, Hongoh R et al (1979) Membrane potential of mitochondria measured with an electrode sensitive to tetraphenylphosphonium and relationship between proton electrochemical potential and phosphorylation potential in steady state. J Membr Biol 49:105-121

21. Jensen BD, Gunter TE (1984) The use of tetraphenylphosphonium $\left(\mathrm{TPP}^{+}\right)$to measure membrane potentials in mitochondria: membrane binding and respiratory effects. Biophys J 45:92

22. Muratsugu M, Kamo N, Kurihara K et al (1977) Selective electrode for dibenzyl dimethyl ammonium cation as indicator of the membrane potential in biological systems. Biochim Biophys Acta 464:613-619

23. Barja G (1999) Mitochondrial oxygen radical generation and leak: sites of production in states 4 and 3, organ specificity, and relation to aging and longevity. J Bioenerg Biomembr 31:347366

24. Santos MS, Santos DL, Palmeira CM et al (2001) Brain and liver mitochondria isolated from diabetic Goto-Kakizaki rats show different susceptibility to induced oxidative stress. Diabetes Metab Res Rev 17:223-230

25. Moreno AJM, Madeira VMC (1991) Mitochondrial bioenergetics as affected by DTT. Biochem Biophys Acta 1060:166-174

26. Riddles PW, Blakeley RL, Zerner B (1983) Reassessment of Ellman's reagent. Methods Enzymol 91:49-60

27. Fryer LG, Parbu-Patel A, Carling D (2002) The anti-diabetic drugs rosiglitazone and metformin stimulate AMP-activated protein kinase through distinct signaling pathways. J Biol Chem 277:25226-25232

28. Brunmair B, Staniek K, Gras F et al (2004) Thiazolidinediones, like metformin, inhibit respiratory complex I: a common mechanism contributing to their antidiabetic actions? Diabetes 53:1052-1059

29. Schafer G (1983) Biguanides: a review of history, pharmacodynamics and therapy. Diabete Metabolisme (Paris) 9:148-163

30. Hermann LS, Melander A (1997) Biguanides: basic aspects and clinical uses. In: Alberti KGMM, Zimmet P, DeFronzo RA, Keen $\mathrm{H}$ (eds) International textbook of diabetes, 2nd edn. John Wiley \& Sons Inc., New York, pp 841-864

31. Wilcock C, Bailey CJ (1994) Accumulation of metformin by tissues of the normal and diabetic mouse. Xenobiotica 24:49-57

32. Davidoff F (1971) Effects of guanidine derivatives on mitochondrial function. III. The mechanism of phenylethylbiguanide accumulation and its relationship to in vitro respiratory inhibition. J Biol Chem 246:4017-4027

33. Petrosillo G, Di Venosa N, Pistolese M et al (2006) Protective effect of melatonin against mitochondrial dysfunction associated with cardiac ischemiareperfusion: role of cardiolipin. FASEB J 20:269-276

34. Majithiya JB, Balaraman R (2006) Metformin reduces blood pressure and restores endothelial function in aorta of streptozotocin-induced diabetic rats. Life Sci 78:2615-2624

35. Tessier D, Maheux P, Khalil A et al (1999) Effects of gliclazide versus metformin on the clinical profile and lipid peroxidation markers in type 2 diabetes. Metabolism 48:897-903

36. Bellin C, de Wiza DH, Wiernsperger NF, Rosen P (2006) Generation of reactive oxygen species by endothelial and smooth muscle cells: influence of hyperglycemia and metformin. Horm Metab Res 38:732-739

37. Kowaltowski AJ, Castilho RF, Vercesi AE (2001) Mitochondrial permeability transition and oxidative stress. FEBS Lett 495: $12-15$

38. Bernardi P, Broekemeyer KM, Pfeifer DR (1994) Recent progress on regulation of the mitochondrial permeability transition 
pore; a cyclosporin-sensitive pore in the inner mitochondrial membrane. J Bioenerg Biomembr 26:509-517

39. Zoratti M, Szabo I (1995) The mitochondrial permeability transition. Biochim Biophys Acta 1241:139-176

40. Bernardi P, Vassanelli S, Veronese P et al (1992) Modulation of the mitochondrial permeability transition pore. Effect of protons and divalent cations. J Biol Chem 267:2934-2939

41. Macho A, Hirsch T, Marzo I et al (1997) Glutathione depletion is an early and calcium elevation is a late event of thymocyte apoptosis. J Immunol 158:4612-4619

42. Le Quoc D, Le Quoc K, Gaudemer Y (1976) Energy-dependent variation of thiol groups reactivity or accessibility in rat liver mitochondria, revealed by measurements of labelled thiol reagents incorporation. Biochem Biophys Res Commun 68:106-113

43. Kowaltowski AJ, Netto LE, Vercesi AE (1998) The thiol-specific antioxidant enzyme prevents mitochondrial permeability transition. Evidence for the participation of reactive oxygen species in this mechanism. J Biol Chem 273:12766-12769

44. Nammour FE, Fayad NF, Peikin SR (2003) Metformin-induced cholestatic hepatitis. Endocr Pract 9:307-309

45. Kutoh E (2005) Possible metformin-induced hepatotoxicity. Am J Geriatr Pharmacother 3:270-273 